\title{
Resenha
}

La societé inclusive, parlons-en! Il n'y a pas de vie minuscule

Charles Gardou

Toulouse: Éditions Érès, 2012, 170 p.

\section{FALEMOS DE UMA SOCIEDADE INCLUSIVA}

\author{
Suely Marques
}

DOl: http://dx.doi.org/10.11606/issn. 1981-1624.v19i1p215-220

O livro La societé inclusive, parlons-en! Il n'y a pas de vie minuscule condensa o pensamento de Charles Gardou e é fruto de um longo percurso no qual o autor se interroga sobre o lugar dado à vulnerabilidade e, em particular, às pessoas em situação de deficiência na sociedade $^{1}$. Esta obra busca esclarecer as múltiplas facetas do conceito de inclusão com base na apreensão das realidades de vida de pessoas em situação de deficiência e suas subjetividades em sofrimento no paradoxal contexto do mundo contemporâneo.

Ao longo do livro, Gardou edifica a noção de sociedade inclusi; va, seu significado e valor, nas suas múltiplas declinações: educação, acessibilidade, formação profissional, políticas etc. Para o autor, o progresso advindo dos avanços tecnológicos mudou o modo de vida de muitos, melhorando a qualidade de vida, por um lado, mas acentuando as desigualdades, por outro. As pessoas em situação de deficiência acompanham, como a sombra à luz, as facilidades cada vez maiores de tantos, em detrimento de suas dificuldades.

Uma questão central permeia todo o livro: "Qual impulso poderá desencadear as profundas transformações, autorizando, enfim, aos mais frágeis a se beneficiarem de seu pleno direito ao patrimônio comum?” (p.13). Contrapondo-se à esperança secular de redução das distâncias sociais, ilhas de comodidade avizinham-se de oceanos

- Psicanalista. Membro do Conselho Administrativo do Collectif Reliance sur les situations de handicap, l'éducation et les sociétés na Université Lumière Lyon 2. Professora em MBA na Universidade São Caetano do Sul (USCS) e no Instituto Nacional de Pós Graduação (INPG), São Caetano do Sul, SP, Brasil. 
de impedimentos e de exclusão. Essa dissimetria, segundo Gardou, não somente revela uma simples carência da sociedade, mas também constitui um sinal de pesar sobre o futuro coletivo.

Recorrendo à antropologia, à filosofia e à política e passando por heróis das mitologias grega, hindu e celta num pensamento aberto e mestiço, o autor organiza sua obra em torno de cinco princípios ou pilares sobre os quais uma sociedade inclusiva pode ser edificada:

1. Ninguém detém a exclusividade do patrimônio humano e social.

2. A exclusividade da norma é ninguém, a diversidade somos todos nós.

3. Não existe vida minúscula ou maiúscula.

4. Viver sem existir é a mais cruel das exclusões.

5. Todo ser humano nasceu para a equidade e para a liberdade.

\section{Ninguém detém a exclusividade do patrimônio humano e social}

O primeiro pilar trata do acesso das pessoas em situação de deficiência ao patrimônio humano e social. Não basta viver no mesmo território para se pertencer a uma comunidade; é necessário poder compartilhar o patrimônio educacional, profissional, cultural, artístico e comunicacional. Para o autor, trata-se de uma patologia social o fato de que, apesar dos diversos textos, leis e engajamentos mundiais, as pessoas em situação de deficiência continuam, em diferentes níveis, a ser objeto de violações de seus direitos em todas as partes do mundo.

\section{A exclusividade da norma é ninguém, a diversidade somos todos nós}

Com base na expressão de Gilles Deleuze, a maioria é ninguém e a minoria somos todos nós, Gardou analisa a noção de diversidade e suas raízes para sedimentá-la como a tradução da "infinita variedade humana e a polifonia de mundos socioculturais" (p. 42). Em uma sociedade em que os encantos de uma perfeição inatingível, de corpos e espíritos que não "disfuncionam", nem envelhecem ou morrem são exaltados, o dever de conformidade assombra a identidade e o sentimento de pertencimento. Esse contexto alimenta, nas pessoas com deficiência, sentimentos de ameaça, desclassificação e desfiliação. Como poderia ser diferente para aqueles que nasceram a despeito dos diagnósticos pré-natais? Quanto mais avançam a ciência e a tecnologia, mais se quesì tiona, em face de certos diagnósticos, que tipo de vida é digna de ser vivida. Para aqueles cujas vidas são objeto de considerações e avaliações

216 Estilos clin., São Paulo, v. 19, n. 1, jan./abr. 2013, 215-220. 
biomédicas, o "normal" constitui o critério decisivo a partir do qual se exerce um controle de qualidade comparável ao praticado na área da produção industrial.

Contrapondo-se a esse cenário, Gardou adverte para uma sociedade inclusiva que se revele pelo pleno direito civil oferecido à diversidade de silhuetas humanas e seus modos de acesso ao mundo. Contrariamente à lógica disjuntiva fundada sobre uma conformidade fantasmática, a sociedade inclusiva caracteriza-se pela capacidade coletiva de conjugar as singularidades. Conforme o autor, "as pessoas em situação de deficiência não constituem um tipo humano à parte. Como todos os seres humanos disseminados pelo planeta, elas são variações sobre um mesmo tema: o frágil e o singular" (p.44).

Resistindo ou cedendo às agressões do infortúnio, circunstâncias diversas podem, sem prevenir, fazer estilhaçar a certeza de estar instalado, como membro irremovível, do bom lado do destino. A vida, por natureza ambígua, pode nos lançar, a cada instante, para fora da condição ordinária ou comum. Ninguém está ao abrigo de tornar-se um estrangeiro da norma coletiva.

Para Gardou, a dialética do singular e do universal situa-se no centro da compreensão do humano e de suas relações sociais: "o pensamento inclusivo eleva-se contra a ação excessiva de uma norma que prescreve, proscreve e asfixia o singular" (p.51). As pessoas em situação de deficiência, associadas a uma categoria abstrata, são uniformizadas e despojadas de suas identidades. A categorização, ressalta o autor, afasta as situações humanas singulares e concretas. Uma sociedade inclusiva defende uma vida comum implicando num desejo de ligação e de interação das singularidades.

\section{Não existe vida minúscula ou maiúscula}

O terceiro pilar da sociedade inclusiva parte do reconhecimento da vulnerabilidade como um aspecto universal do ser humano. $\mathrm{O}$ autor chama a atenção do leitor para essa marcante característica da condição humana, notadamente no início e no fim da vida, porém insistentemente colocada à sombra pela sociedade em seu desejo fantasmático de onipotência. "Entre o nascimento e a morte, a possibilidade de se machucar, não fisicamente, mas ontologicamente, banha cada existência. Essa imperfeição e o fim que ela anuncia são olhados como o sol: nunca diretamente" (p.65). A deficiência apresenta-se como um espelho de aumento, escancarando nossa impotência. Para Gardou, dentre as fontes profundas de uma sociedade inclusiva está 
a oposição à sacralização da potência, herdeira do darwinismo social. A sociedade inclusiva implica em uma inteligência coletiva das vulnerabilidades. $\mathrm{O}$ autor condena o lugar reservado àqueles que foram assujeitados e tornados impotentes por um sistema dominante que minora ou anula suas possibilidades e duvida de sua plena qualidade humana. "O desejo de estima social, que funda a autoestima, define o homem. Sua luta por reconhecimento não é nem uma fraqueza nem uma pretensão, mas sim a particularidade da sua espécie e razão de ser de sua vida social" (p. 74). O autor remarca que quanto mais visível é a deficiência, mais invisíveis nos tornamos socialmente e mais as pessoas recusam-se a nos ver. Dessa situação nasce o cansaço resultante do esforço de reafirmar para si próprio uma existência no mundo real. As pessoas em situação de deficiência sentem-se sós, atravessadas por um deserto social.

A violência simbólica do vocabulário depreciativo historicamente utilizado para designar as pessoas em situação de deficiência é questionada por Gardou que propõe o abandono das palavras fronteiriças em prol de palavras "de ligação". Termos comuns em vez de termos particularizantes, favorecendo situar as pessoas no movimento geral.

Uma sociedade inclusiva necessita de palavras e conceitos compartilhados, inclusivos, em coerência com o direito de todos ao patrimônio social sem, entretanto, apagar a diversidade e a especificidade de situações.

\section{Viver sem existir é a mais cruel das exclusões}

Gardou inicia este capítulo apontando a diferença entre o viver ligado ao aspecto biológico e o existir específico dos homens marcados por sua precocidade ao nascer e por sua natureza social. A deficiência coloca em evidência o caráter sempre problemático do acesso ao existir. Cuidadas por todos, as pessoas em situação de deficiência podem morrer por não existirem para ninguém. As respostas atentas às suas necessidades biológicas de sobrevivência não garantem, por si só, a possibilidade de existir. Os cuidados em suas dimensões terapêuticas não são suficientes. Estão nas mãos de outros que decidem por eles, que tomam conta deles sem considerá-los sujeitos e atores de suas próprias histórias.

Passando pela questão do suicídio e casos de morte assistida, o autor ressalta a intensidade da luta, às vezes perdida, contra os obstáculos ao acesso à existência. Permitir existir a uma pessoa

218 Estilos clin., São Paulo, v. 19, n. 1, jan./abr. 2013, 215-220. 
fragilizada por uma deficiência dá relevo à valorização de suas capacidades e talentos de intensidade e expressão variáveis, sob suas limitações aparentes. A negação de suas aptidões aniquila o desejo de se lançar e projetar. Além disso, permitir às pessoas com deficiência existir é reconhecer seus desejos. Constantemente reduzidos às suas necessidades especiais, as pessoas em situação de deficiência são consideradas "necessitadas" e seus desejos seriam, portanto, supérfluos, ou mesmo incongruentes. Suas necessidades satisfeitas não seria suficiente? As instituições, legislações e políticas tendem a esquecer e negligenciar gostos e opiniões, aspirações, medos, ideais e sonhos, tão contrariados e votados ao segredo que acabam por se perder. Se as pessoas com deficiência necessitam, por exemplo, de um acompanhante para remediar suas dificuldades, elas desejam poder dizer algo sobre a escolha desta pessoa, o que releva o desejo e não suas necessidades. Outro ponto que o autor explicita é que existir implica em lhes ouvir a despeito, muitas vezes, da ausência de palavras. Eles desejam exprimir-se em seu próprio nome. Desejam poder dizer "eu" para contar uma história que lhes pertence e que não pode ser desconsiderada ou manipulada ao sabor de sentimentos, concepções e interesses alheios. Suas vozes e expertises jamais devem ser desconsideradas nas deliberações e decisões relativas ao seu cotidiano, propondo, se necessário, assistentes para a comunicação e a formulação de seu ponto de vista. Permitir existir, por fim, significa se liberar dos medos ancestrais e ignorâncias supersticiosas. A lista é grande de ideias preconcebidas, preconceitos e estereótipos. O movimento inclusivo requer novas luzes para se liberar definitivamente dos restos de arcaísmos no inconsciente coletivo que cria barreiras à educação, ao emprego e à participação nas políticas sociais.

\section{Todo ser humano nasceu para a equidade e liberdade}

No quinto fundamento, o autor parte da filosofia política de Hobbes, Rousseau, Locke e Kant, aproximando-se das teorias econômicas mais recentes de Rawls e Sen. Ele afirma que uma sociedade inclusiva é uma sociedade consciente de que a igualdade formal não assegura a igualdade real, podendo anular a equidade e a liberdade dos sujeitos. A concepção de justiça deve ir além da simples igualdade de meios para que a justiça considere a liberdade de cada um para realizar suas atividades e se realizar em uma existência digna. ${ }^{2}$

O livro todo, portanto, constitui um belíssimo convite ao questionamento da forma cultural atual, em que a doença, a deficiência, a 
fragilidade e a morte são silenciadas. O autor critica uma sociedade que despoja os mais vulneráveis de sua parte legítima do patrimônio comum e lhes confisca insidiosamente o direito de ter direito.

\section{NOTAS}

1. Ver Gardou, C. (2005). Fragments sur le handicap et la vulnérabilité. Pour une révolution de la pensée et de l'action. Ramonville Saint-Agne: Èrés; Gardou C. e Kristeva, J. Accompagner tous les plus vulnérables. Le Monde, 3 de setembro de 2003; Gardou, C. (2009). Au nom de la fragilité - Des mots d'écrivains. Toulouse: Érés; Gardou, C. (2009). Pascal, Frida Kablo et les autres... ou quand la vulnérabilité devient force. Toulouse: Érès.

2. Referência ao pensamento de Amartya Sen e sua concepção de justiça nas situações concretas. Sen, A. (2009). A ideia de justiça. São Paulo: Companhia das letras.

suelymq@gmail.com

Av. Deputado Rubens Granja, 38 04298-000 - São Paulo - SP - Brasil. 